\title{
Panorama da Linguística Experimental no Brasil
}

\section{An Overview of Experimental Linguistics in Brazil}

\section{Marcus Maia}

Universidade Federal do Rio de Janeiro, Rio de Janeiro, Rio de Janeiro / Brasil

$\mathrm{CNPq}$

maiamarcus@gmail.com

A linguagem é uma faculdade da mente humana e, como tal, é implementada por processos cognitivos complexos. Os estudos linguísticos baseados na inspeção de corpora podem analisar os produtos destes processos, o que tem, sem dúvida, permitido descobertas importantes sobre as línguas. Entretanto, naturalmente, esses estudos estão restritos aos dados que inspecionam, não sendo capazes, por definição, de examinar os processos que geraram tais produtos. Se restrita à análise de corpora, portanto, a pesquisa linguística ficaria impossibilitada de testar hipóteses sobre questões lingüísticas fundamentais, como por exemplo a gramaticalidade ou a aceitabilidade das expressões linguísticas.

Como discutimos em Maia (2015), para estudar tais processos, a gramática gerativa propôs, desde a sua criação, em meados dos anos 50 , que julgamentos sobre a boa formação de frases fossem coletados. Buscando uma caracterização da capacidade gerativa da linguagem, Noam Chomsky propôs que a gramaticalidade das frases poderia ser testada através de julgamentos intuitivos obtidos informalmente pelo linguista consigo próprio e/ou com alguns falantes. Embora o próprio Chomsky tenha avaliado, posteriormente, que a confiabilidade exclusiva da teoria em julgamentos intuitivos informais deveria ser substituída por critérios mais rigorosos, ${ }^{1}$ o fato é que a coleta de julgamentos informais

\footnotetext{
1 "Como qualquer outra pessoa, também não gosto de me fiar em intuições. Devemos substituir as intuições por critérios rigorosos, assim que pudermos". (cf. CHOMSKY discussion in HILL, 1962, p. 177)
} 
introspectivos sobre a aceitabilidade ou sobre a gramaticalidade de frases tem sido a principal ferramenta de avaliação de dados em linguística gerativa há várias décadas. Sua proposição inicial foi verdadeiramente revolucionária em um momento da história da ciência dominada pelo behaviorismo antimentalista. Por meio desses testes informais, a linguística gerativa pôde operar uma mudança importante no foco dos estudos lingüísticos, que pôde ir além das análises exaustivas dos corpora para oferecer uma modelagem inicial dos processos cognitivos subjacentes ao conhecimento da linguagem.

Desde esses dias pioneiros, os experimentos lingüísticos têm percorrido um longo caminho no sentido de adotarem-se critérios mais rigorosos, utilizando metodologias e tarefas engenhosas, análises estatísticas apropriadas e até mesmo os equipamentos sofisticados dos laboratórios de psicolinguística, podendo oferecer evidências independentes, além das intuições iniciais do linguista, para explorar os processos cognitivos da linguagem.

O presente número da Revista de Estudos da Linguagem - RELIN reúne uma amostra significativa de estudos experimentais realizados no Brasil. São 24 artigos, representando as principais técnicas experimentais em uso no mundo para explorar o conhecimento da linguagem, flagrando processos linguísticos off-line e on-line, tais como os testes de ranqueamento em escala, o julgamento controlado de gramaticalidade, $\mathrm{o}$ julgamento de valor de verdade, o teste Cloze, o paradigma de priming, a decisão lexical, a leitura automonitorada, a tarefa maze, a extração de potenciais evocados, o rastreamento ocular, entre outros. Esses estudos investigam diferentes aspectos de questões fonéticas, fonológicas, morfológicas, sintáticas, semânticas e pragmáticas, bem como questões de interface entre vários desses subsistemas do conhecimento linguístico, oferecendo um panorama amplo da Linguística Experimental no país.

Antes de passarmos à apresentação de cada um dos artigos, queremos destacar ainda um fato que é também digno de nota a respeito do presente volume da RELIN: três dos trabalhos aqui reunidos tomam como objeto de suas pesquisas experimentais dados obtidos junto a falantes de línguas indígenas brasileiras, a saber, a língua Maxakalí (família Jê), a língua Yudjá (Tronco Tupi) e a língua Karajá (Tronco Macro-Jê). Como se sabe, foi apenas muito recentemente que a pesquisa de campo com línguas indígenas começou a beneficiar-se do método experimental. Já era tempo que a revolução cognitivista chegasse à linguística de campo e esse 
número da RELIN situa-se entre os primeiros a publicar estudos dessa natureza no Brasil. Este novo empreendimento, que está sendo chamado, justamente, de pesquisa de campo experimental, está enfrentando o desafio de reunir dimensões cruciais da linguística, como as diferentes teorias, os métodos psicolinguísticos e os procedimentos etnográficos de campo, a fim de tentar explorar processos gramaticais que dificilmente poderiam ser descobertos apenas com base em análise de corpora.

Feito este destaque, passemos à apresentação dos artigos. Após a resenha do primeiro artigo, de natureza metodológica, seguem-se cinco artigos que estudam questões fonéticas e fonológicas ou de interface entre a fonologia e a sintaxe. Apresentam-se, na sequência, artigos que discutem questões de processamento e de representação gramatical e um grupo de artigos que tem como objeto a relação de concordância. Os próximos quatro artigos debruçam-se sobre o tema da referência nominal. Seguem-se três artigos que estudam experimentalmente aspectos da aquisição da linguagem, o último deles investigando questões relativas à distributividade em uma língua indígena, tema também abordado pelo artigo seguinte, com falantes adultos de outra língua indígena. O processamento bilíngue é tema de dois artigos. A revista encerra com dois artigos de viés aplicado sobre o tema da leitura.

Em um momento em que a possibilidade de experimentação vem atraindo pesquisadores de praticamente todas as subáreas da Linguística, o artigo de Sampaio que abre o volume, intitulado A escolha de software e hardware na psicolinguística: revisão e opinião oferece orientações seguras da psicolinguística, principalmente para os recém-chegados ao campo fascinante dos métodos experimentais. Em um texto bastante didático, Sampaio discorre sobre os diferentes programas usados na implementação de experimentos, sugerindo uma série de critérios a serem considerados na sua escolha, além de oferecer informações práticas que podem poupar tempo para os linguistas decididos a explorar metodologias experimentais.

Cinco estudos neste número investigam fenômenos fonéticos, fonológicos ou na interface fonologia-sintaxe. Em Maxakalí nasality and field recording with earbud microphony, Nevins e Silva iniciam revendo dados da língua indígena Maxakalí (família Jê) que demonstram que esta lingua tem processos fonológicos tais como prénasalização, nasalização em coda, harmonia nasal dentro da sílaba, entre núcleo e rima, entre rima e onset e de sílaba a sílaba, que oferecem 
desafios interessantes para as teorias fonológicas. Após discutirem as técnicas mais tradicionalmente utilizadas no estudo da nasalidade, os autores apresentam a sua proposta inovadora de fonologia de campo experimental: a técnica de gravação com microfonia de fone de ouvido, que é, então, demonstrada em relação a fenômenos de nasalidade vocálica e consonantal, empréstimos, entre outros fenômenos na língua Maxakalí. Ao final, os autores fazem ainda uma interessante prospecção de áreas que a técnica de microfonia de fone de ouvido poderia vir a impactar positivamente, incluindo questões pedagógicas.

No artigo Social affective variations in Brazilian Portuguese: a perceptual and acoustic analysis, Rilliard e Moraes partem de um experimento de escolha livre com 22 ouvintes brasileiros para analisar parâmetros prosódicos de duração, intensidade e entonação, tomando como quadros de referência para a análise, teorias de expressividade na fala e de uso simbólico da voz em interações verbais. Os autores descrevem agrupamentos de expressões, rotulando-as como "pergunta neutra", "admiração", "arrogância", "autoridade", "desprezo", "obviedade", "incerteza", "ironia", "irritação", "pisando em ovos", "polidez", "sedução", "sinceridade", "surpresa", "descrédito", entre outras expressões. Os resultados do estudo permitem aos autores reagrupar dezessete expressões em três grupos principais de valência positiva, assertividade e dubitatividade. Os autores comparam ainda os dados brasileiros com dados obtidos com franceses e japoneses, para concluirem que os dados brasileiros apresentam maior acurácia na singularização de expressões únicas, em comparação com as duas outras línguas.

Também pesquisando a percepção de emoções na fala, Silva e Barbosa discutem no artigo Perception of emotional prosody: investigating the relation between the discrete and dimensional approaches to emotions, as relações entre a percepção de emoções básicas e suas dimensões emocionais na fala, conduzindo dois experimentos de percepção de enunciados em uma língua estrangeira sobre a qual os participantes não tinham qualquer conhecimento. Com base nesses experimentos, os autores puderam correlacionar as dimensões emocionais ativação, justiça, valência, motivação e envolvimento com as emoções básicas alegria, raiva, tristeza e calma. Em seguida, as emoções básicas e dimensões emocionais foram correlacionadas com parâmetros acústicos, confirmando que os ouvintes, de fato, utilizam ao menos parcialmente traços acústicos para julgar a expressividade das emoções 
e dimensões emocionais. Ao final, os autores sugerem que esse tipo de investigação tem potencial para contribuir com pesquisas sobre a síntese da fala e sobre o reconhecimento automático de emoções.

Em Prosódia de enunciados declarativos e interrogativos totais nas variedades de Salvador, Fortaleza e Rio de Janeiro, Rebollo Couto, Silva e Miranda gravam enunciados declarativos e interrogativos, elicitando-os a partir de imagens. As autoras avaliam que esses dados de fala experimental, assim coletados, seriam mais próximos dos dados de leitura do que dos dados provenientes de fala atuada, em que o falante já conhece o texto, tendo praticado previamente a sua elocução. Os participantes da pesquisa são adultos de escolaridade média, de ambos os sexos, originários de Salvador, Fortaleza e Rio de Janeiro, havendo os dados obtidos no teste, sido analisados acusticamente no programa PRAAT em termos de parâmetros acústicos de F0, duração e intensidade das vogais pré-tônicas, tônicas e pós-tônicas. Os resultados das análises dos dados obtidos no experimento são comparados a resultados de pesquisas similares nas três capitais, permitindo aos autores demonstrar a existência de diferenças prosódicas entre as modalidades declarativa e interrogativa testadas, bem como variações dialetais.

Angelo e Santos apresentam em Desambiguização de sentenças na interface fonologia-sintaxe os resultados de um experimento do tipo oral sentence/picture matching (pareamento de sentença auditiva e imagem), com o objetivo de analisar como pistas de duração na desambiguação de sentenças do tipo SN1-Verbo SN2-Atributo influenciam a interpretação dos ouvintes. $\mathrm{O}$ artigo situa-se em uma linha de pesquisa muito produtiva que vem testando o princípio de processamento Late Closure (Aposição Local) em diferentes construções em várias línguas. As autoras apresentaram frases como "A mãe encontrou a filha suada" em contextos que favoreciam ora a interpretação do tipo early closure (a mãe estava suada) ou a interpretação late closure (a filha estava suada), manipulando também no input auditivo a duração do trecho entre a sílaba final do objeto até a sílaba inicial do atributo, enquanto os participantes visualizavam imagens que deveriam escolher, de acordo com a interpretação das frases que ouviam, levando em conta ainda gradações no alongamento. Os resultados obtidos demonstram a operação do princípio Late Closure, (cf. FRAZIER, 1979), em português brasileiro, corroborando o trabalho de Magalhães e Maia (2006), segundo o qual uma preferência pelo default local ocorre na ausência de pistas prosódicas. 
Diversos estudos neste volume apresentam resultados experimentais sobre a compreensão adulta de construções sintáticas que, além de fornecerem evidências relevantes para teorias de processamento, também estabelecem diálogo com questões de representação gramatical. Em Representation and Processing of the Inflected Infinitive in Brazilian Portuguese: an eye-tracking study, Modesto e Maia apresentam estudo de rastreamento ocular que indica menor custo significativamente para o processamento da correferência entre antecedentes acessíveis na frase e a categoria vazia PRO do que nos casos em que a interpretação do PRO é arbitrária. Em linha com a literatura psicolinguística relativa aos chamados modelos de "dois estágios", que têm estabelecido como default no processamento sintático a computação intrassentencial "syntax first", precedendo a extrassentencial, os achados de Maia e Modesto são também pertinentes para contribuir com dados empíricos para debate corrente na teoria sintática e na descrição da gramática do português brasileiro, constituindo, neste sentido, empreendimento realizado não só no quadro de referência da especialidade do processamento de frases, mas também no quadro da especialidade relativamente mais recente da sintaxe experimental. A literatura de natureza teórica, descritiva e também sociolinguística sobre o infinitivo flexionado em português é revisada criteriosamente na primeira parte do artigo, sugerindo-se que "os contextos sintáticos de uso da flexão não finita no Brasil atual e a interpretação de tais estruturas são questões de grande interesse científico, considerando-se a situação sociopolítica do país". O ponto fulcral do debate sobre a representação do infinitivo flexionado em português situa, de um lado, a análise de Rodrigues e Hornstein (2013), que afirma que as construções com infinitivo flexionado em português são configurações de controle não obrigatório e, de outro, a análise de Modesto (2010, 2016a), que argumenta serem os sujeitos de orações não finitas flexionadas normalmente interpretados como sujeitos controlados em PB. Os resultados do experimento, que indicam que as construções com PRO controlado em frases com verbos infinitivos flexionados não apenas são psicologicamente reais, mas são, de fato, a opção preferida em uma comparação estrita com o PRO de interpretação arbitrária, servem de fundamentação empírica para a conclusão em favor da proposta de Modesto (2010, 2016a).

No artigo On the asymmetry between subject and object relative clauses in discourse context, Forster e Corrêa também 
examinam, através de experimento de rastreamento ocular, questão de processamento com relevância para a teoria gramatical minimalista. Realizado no âmbito do quadro maior do projeto de pesquisa da segunda autora, intitulado "Processamento e aquisição da linguagem sob ótica minimalista: extensão e comparação de modelos", o estudo toma como objeto de investigação a assimetria existente no processamento de orações relativas de sujeito vis à vis o processamento de orações relativas de objeto, manipulando como uma das variáveis independentes do experimento o contexto narrativo em que a oração relativa é apresentada, que poderia favorecer o seu processamento como relativa de sujeito ou de objeto. $\mathrm{O}$ experimento tinha, portanto, um design $2 \times 2$, contendo 40 narrativas (20 favorecendo a relativa de objeto, outras 20 a relativa de sujeito), distribuídas em quadrado latino e apresentadas a 41 participantes, para leitura, ranqueamento e interpretação. Os resultados obtidos indicam maior custo para as relativas de objeto do que para as relativas de sujeito, independentemente do contexto discursivo. Destaque-se que os autores avaliam seus resultados não só em termos de teorias de processamento, trazendo à discussão o debate clássico em psicolinguística entre modelos de dois estágios versus estágio único, mas também, interessantemente, em termos de desenvolvimentos recentes da linguística gerativa que, como já tem apontado o grupo de pesquisa dos autores (LAPAL), vem minimizando as diferenças que, tradicionalmente, tem colocado em oposição os modelos de um e dois estágios.

$\mathrm{O}$ artigo $\mathbf{A}$ aceitabilidade da anáfora logofórica em português brasileiro, de Souza, Oliveira e Henrique, oferece um exemplo paradigmático de empreendimento em sintaxe experimental. Considerando explicitamente em seu texto que a intuição do linguista poderia não ser suficiente para permitir avaliar adequadamente a aceitabilidade das construções logofóricas em PB, tema do artigo, as autoras desenvolvem um estudo controlado, ainda que não cronométrico, de julgamento de aceitabilidade para testar sentenças com anáfora (e.g. $\mathrm{O}$ genro de Mauro cortou José e ele mesmo com a faca na cozinha) e com pronome (e.g. O genro de Mauro cortou José e ele com a faca na cozinha) logofóricos. Segundo avaliam no texto, as intuições das autoras, ponto de partida do estudo, indicavam que ambas as construções pudessem ser aceitáveis em PB, o que se revelou inadequado, como demonstrado pelos resultados obtidos no teste, em que a aceitabilidade dos pronomes logofóricos não atingiu níveis de significância. As autoras discutem 
seus resultados com base em teorias de representação como a Teoria da Ligação (CHOMSKY, 1981) e, principalmente, com base na Teoria da Reflexividade de Reinhart e Reuland (1993). Além da interessante discussão empreendida pelas autoras, fica comprovada no estudo a importância da máxima frequentemente mencionada na especialidade da sintaxe experimental: as intuições devem ser ponto de partida, mas não ponto de chegada das pesquisas.

Um tema em foco em estudos recentes em psicolinguística e em sintaxe experimental é o processamento da concordância que, segundo Phillips, Wagers e Lau (2011), tem constituído um desafio para os psicolinguistas interessados em pesquisar a compreensão on-line das construções gramaticais. Phillips e colegas avaliam que, nas construções que envolvem concordância, o processador sintático parece mais suscetível à falibilidade, ao contrário do que ocorre em outras construções (e.g. efeitos de ilha, dependências entre antecedentes e categorias vazias, princípios de Binding), em que o processador demonstra "sensibilidade on-line impressionante" (cf. p. 149). O tema da concordância requer, portanto, muita pesquisa para que possamos vir a compreender melhor como os falantes "navegam representações linguísticas complexas em tempo real", ${ }^{2}$ como avaliam os autores, após um levantamento abrangente da literatura. No presente número da RELIN, três artigos se propõem a contribuir, através de experimentos, para avançar nosso entendimento da relação de concordância.

Em Efeitos de distância linear e marcação no processamento da concordância verbal variável em PB, Marcilese, Rodrigues, Augusto e Henrique estudam a computação das relações de concordância entre sujeito e verbo, manipulando a distância linear entre esses elementos, em um teste do tipo maze task ou labirinto, em que os participantes devem escolher, entre duas opções, como continuar a leitura de uma frase. Interessantemente, os autores partem de achados da sociolinguística variacionista, que têm indicado, sistematicamente, a relevância da distância linear entre sujeito e verbo na realização em corpora da concordância verbal em português brasileiro. Após rever criteriosamente esses estudos e também a literatura pertinente em psicolinguística, as

2 "...the parser's highly selective vulnerability to interference and "gramatical illusions" provides a valuable tool for understanding how speakers encode and navigate complex linguistic representations in real time" (cf. PHILLIPS; WAGERS; LAU, 2011, p. 147.) 
autoras se propõem a estudar, para além dos produtos encontrados nos corpora, o processo cognitivo de concordância, manipulando a distância linear como uma das variáveis independentes do experimento, ao lado dos fatores número do verbo e número do sujeito. Seus resultados indicam não só a existência de efeito de distância linear no processamento da concordância, mas também "apontam para a relevância da marcação na atuação dos mecanismos de verificação de traços". O artigo é concluído reconhecendo-se a importância de empreendimentos interdisciplinares, como o que foi realizado no estudo em tela, buscando um "diálogo explícito" entre variação e processamento, para se conseguir avançar no entendimento de fenômenos linguísticos complexos como a concordância.

$O$ tema da marcação da concordância em PB é também investigado em Agreement effects of gender and number in pronominal coreference processing in Brazilian Portuguese, em que Alves reporta um estudo de rastreamento ocular que tem como objetivo específico o de explorar como e quando as condições estruturais impostas pelo Princípio B da Teoria da Ligação (CHOMSKY, 1981) interagem com pistas de concordância, na recuperação mnemônica de antecedentes por pronomes. A autora mede a duração de fixações oculares em áreas críticas de frases apresentadas a 24 participantes, para testar a hipótese de que a redundância na marcação morfológica da concordância em PB levaria os leitores a utilizar tais pistas na recuperação de antecedentes por pronomes. São encontrados efeitos tanto de antecedentes estruturalmente aceitáveis, quanto de antecedentes não aceitáveis estruturalmente, levando a autora a alinhar-se com os achados de Badecker e Straub (2002), contrariando a hipótese de que as condições estruturais atuem como um filtro inicial no processamento. Finalmente, tomando como base seus resultados, a autora também argumenta em favor do modelo CAMcontent addressable memory, que propõe que informações previamente analisadas possam ser recuperadas a partir de uma busca, em paralelo, de pistas gramaticais, como as oferecidas pela marcação da concordância de número e de gênero em $P B$.

O terceiro artigo que investiga experimentalmente a relação gramatical de concordância em PB é A behavioral study to investigate the processing routes of grammatical gender in Brazilian Portuguese, de Resende e Mota. Diferentemente dos dois estudos anteriores, este artigo focaliza as relações de concordância no âmbito do Sintagma Determinante (DP), para pesquisar possíveis diferenças nas rotas de 
processamento da concordância de gênero em duas condições, a saber, artigo e nome (condição 1) e nome e adjetivo (condição 2) em uma tarefa em que se mediram tempos de reação dos participantes nas duas condições, contrastando-se também substantivos masculinos e femininos, transparentes quanto ao seu gênero gramatical (terminações -a e -o) e opacos (outras terminações). Os resultados obtidos indicam a existência de diferenças no processamento da concordância de gênero entre as condições 1 e 2, atribuídas à maior quantidade de informação a ser processada na relação entre o nome e adjetivo do que na relação entre o artigo e o nome. As autoras também encontram efeitos de frequência e de memória, influenciando tanto o processamento de formas transparentes, quanto de formas opacas, o que as leva a concluir em favor dos modelos unitários, não duais, de processamento da linguagem.

O importante tema da referência de nomes é explorado através de angulações teóricas e de metodologias diversas, em quatro artigos, neste número da RELIN, devotado à Linguística Experimental. Em A influência da referencialidade no processamento de orações relativas em português brasileiro, Bezerra, Leitão e Medeiros, testam, em estudos de leitura automonitorada e de rastreamento ocular de orações relativas do $\mathrm{PB}$, o Princípio da Referencialidade, apresentado no âmbito do modelo Construal (FRAZIER; CLIFTON, 1996), que prediz que orações adjetivas restritivas sejam preferencialmente apostas a núcleos referenciais. Os autores se colocam o desafio de tentar flagrar através de medidas on-line efeito de referencialidade operando a tempo de influenciar as decisões do processador sintático. Como, a partir do modelo Construal, relações sintáticas secundárias (como as orações relativas), seriam associadas e não apostas (casos restritos à aposição de argumentos, em relações sintáticas primárias), no marcador frasal em construção, o processador seria capaz de avaliar informação semântica e pragmática para informar suas decisões, ao contrário das propostas iniciais do tipo "syntax-first" da Teoria do Garden-Path. Os autores corroboram em PB as propostas do modelo Construal e discutem similaridades e diferenças entre os resultados obtidos nos experimentos de leitura automonitorada e de rastreamento ocular, este último viabilizado graças à cooperação entre os laboratórios LAPROL (UFPB) e LAPEX (UFRJ).

Em An ERP study of kind-denoting nouns in subject position in Brazilian Portuguese, França, Maurício e Infantosi colocam em contraste uma abordagem do tipo "syntax-first", inspirada no Programa 
Minimalista (cf. CHOMSKY, 1995) e uma abordagem do tipo "semanticfirst", que toma como referência propostas de natureza cognitivista de Fillmore $(1982,2007)$. Para estabelecer o contraditório entre as duas abordagens os autores tomam como objeto do estudo o tema central da referencialidade, orquestrando de forma bastante lógica e clara, em estudo de extração de potenciais cerebrais evocados, a comparação entre Sintagmas Nominais de denotação específica e Sintagmas Nominais que denotam tipo em um contexto especial de conhecimento de mundo. A hipótese do estudo é a de que, em linha com a abordagem "syntaxfirst", os nomes que denotam tipo, em posição de sujeito, não deverão influenciar o processamento em medidas iniciais em que o conteúdo semântico do nome não deveria ser acessado. De fato, monitorando 34 participantes através de equipamento de EEG com 20 canais, enquanto estes realizavam julgamentos de gramaticalidade de frases em que as condições experimentais eram contrastadas, tomando-se como controle condições incongruentes que deveriam produzir ERP(N400), os autores puderam concluir que "o pleno acesso ao conteúdo pragmático que está no sujeito só ocorre após o merge do complemento ao verbo".

\section{$\mathrm{O}$ artigo Referência genérica em SNs singulares: uma} abordagem cognitivista experimental de Pinheiro, Ferrari, Pimenta, Souza, Viegas e Ohenes, também estabelece como objeto de estudo aspectos da referencialidade de nomes, mas adota perspectiva teórica diametralmente oposta à do estudo apresentado no parágrafo acima, tomando como quadro de referência a Gramática Cognitiva (cf. LANGACKER, 1987, 2013, entre outros), que propõe caracterização de base semântica de sintagmas nominais. Os autores postulam, inicialmente, a existência de uma diferença conceptual entre o SN genérico definido (e.g. o gato é voluntarioso) e o SN genérico indefinido com determinante zero (e.g. gato é voluntarioso). Alinhando-se com o que chamam de "guinada empírica" em Linguística Cognitiva" (cf. STEFANOWITSCH, 2011), os autores se propõem, em seguida, a tentar estabelecer experimentalmente o efeito que uma sequência com contraste poderia exercer sobre o SN singular genérico com artigo definido, manipulando a presença e a ausência dessas sequências contrastivas nos estímulos (e.g. A criança gosta de doces e guloseimas vs A criança gosta de doces e guloseimas. Já o adulto tende a ter um paladar mais apurado). Em uma tarefa off-line de julgamento de aceitabilidade controlada, utilizando uma escala Likert de cinco pontos, os autores testaram 30 participantes para 
comparar frases como exemplificadas acima, distribuidas em quadrado latino. Após analisar seus resultados, os autores concluem que podem “confirmar a previsão de que a presença de um segundo SN genérico, com função contrastiva, na mesma sequência textual eleva significativamente a aceitabilidade de enunciados com SN genérico definido". Tratando-se de experimento off-line, este resultado não pode, portanto, ser usado para comparar questões de curso temporal, com possível impacto na arquitetura da representação e do processamento linguísticos, a partir do exame da referencialidade de nomes, como as entretidas nos dois estudos apresentados anteriormente, que utilizam variáveis dependentes on-line. Ainda assim, a perspectiva de início de um programa de pesquisa experimental em Linguística Cognitiva, de que esse trabalho é, sem dúvida, um dos precursores no Brasil, tem o potencial de trazer para o exame empírico criterioso da Linguística Experimental questões que tradicionalmente têm fundamentado divergências importantes e, muitas vezes, motivado debates acalorados, em Linguística.

$\mathrm{O}$ artigo assinado por Ribeiro e Ricci, intitulado Um estudo experimental do processamento de metáforas do português brasileiro também examina uma questão relacionada à referência de nomes, a saber, a computação do sentido literal e não literal ou metafórico. Depois de relatar dois estudos normativos bastante criteriosos, que lhes permitiram estabelecer, com confiança, controles relativos à familiaridade, adequação e convencionalidade das metáforas nominais, os autores reportam um estudo de leitura automonitorada em que foram apresentadas a 66 participantes, em distribuição em quadrado latino, frases alvos precedidas de três tipos de contextualizações, motivando interpretação metafórica, interpretação literal, inclusão em classe. Não tendo observado diferenças significativas nos tempos médios de leitura dos segmentos críticos, nas três condições, os autores argumentam em favor do processamento direto de metáforas familiares, conforme preconizado por Glucksberg e Keysar (1990), habilmente rebatendo o chamado argumentum ad ignorantiam (a ausência de evidência não é evidência da ausência), com base no poder do teste estatístico utilizado na análise dos dados.

Três estudos no presente número temático da RELIN investigam experimentalmente a aquisição da linguagem. Em A técnica de ERP no processamento de sentenças de crianças: uma revisão, Costa presta uma contribuição para a área de aquisição da linguagem, revisando estudos que têm utilizado a técnica de extração de potenciais cerebrais 
evocados por eventos linguísticos, incluindo um estudo seu próprio (Costa, 2015), desenvolvido para sua tese de doutorado. O artigo inicia com uma apresentação bastante didática da técnica EEG-ERP, destacando sua excelente resolução temporal e seu baixo custo, comparativamente a técnicas tais como o MEG, o fMRI, o PET, entre outras. O artigo, então, passa a rever componentes cerebrais frequentemente encontrados em experimentos com adultos, com especial atenção para o N400 e o P600. Passa-se a discutir, em seguida, as razões pelas quais estudos encefalográficos ainda são incipientes em estudos com crianças, revendose, na sequência, estudos de segmentação da fala e de processamento de sentenças. Costa conclui seu artigo apresentando o relato de seu próprio experimento, em que testou crianças francesas quanto à estrutura argumental de verbos. Ela relata haver captado uma ativação negativa entre 200-450ms após as crianças terem escutado o verbo que estava sendo manipulado, o que lhe permite estabelecer que as crianças são sensíveis a manipulações na estrutura argumental.

Em Aquisição de estruturas possessivas inalienáveis: o caso dos nomes de parte do corpo em inglês americano e português brasileiro, Mendes faz sintaxe experimental ao estudar construções de posse inalienável em $\mathrm{PB}$ e em inglês, comparando o desenvolvimento dessas estruturas na criança com as propriedades que as caracterizam na gramática adulta. Após rever a literatura teórica relevante (e.g. Teoria da Ligação, CHOMSKY, 1981, entre vários outros trabalhos teóricos), bem como pesquisas sobre a posse inalienável e sua aquisição, a autora estabelece suas hipóteses e previsões, que serão testadas em uma série de experimentos de julgamento de valor de verdade. Através desses experimentos, testa-se a compreensão de falantes de inglês americano e de $\mathrm{PB}$ a respeito da ocorrência de determinantes definidos e pronomes possessivos em construções de posse em que, tanto a leitura alienável, quanto a inalienável, estariam disponíveis. Os resultados obtidos permitem à autora concluir que, embora partindo da mesma gramática universal, a distinção entre as gramáticas do PB e do inglês americano apareceu por volta dos seis anos de idade, quando as crianças falantes de inglês americano passaram a limitar o uso do determinante definido, de acordo com a gramática alvo.

No artigo On the Acquisition of distributivity in Yudja, Lima faz semântica formal experimental, estudando a aquisição da distributividade na língua índigena brasileira Yudja, comparativamente a adultos, através 
de testes de preferencialidade. Após rever cuidadosamente a literatura relevante tanto em semântica formal, quanto em psicolinguística, Lima estabelece os objetivos da pesquisa: (i) avaliar a disponibilidade da interpretação distributiva encoberta em Yudjá e (ii) explorar a interpretação de frases que marcam a distributividade abertamente na língua, através do processo de reduplicação verbal. Lima descreve, em seguida, as propriedades dos sintagmas nominais e verbais na língua, com especial atenção para a formação da reduplicação verbal, apresentando sua análise teórica sobre a reduplicação e a pluralização de nomes em Yudjá, para então testar experimentalmente a hipótese já formulada em Lima (2008) de que a reduplicação verbal, além de indicar pluralidade, funciona também como um marcador da distributividade aberta na língua. Os resultados dos testes de preferencialidade levados a efeito com onze adultos e dezessete crianças, que a autora considera serem pilotos de futuras pesquisas, indicaram que, enquanto a interpretação dos adultos é influenciada pelo tipo de sintagma nominal, as crianças teriam preferência pela leitura distributiva, independentemente das propriedades do verbo e dos sintagmas nominais.

O trabalho de Silva, intitulado $O$ processamento do numeral reduplicado sohoji-sohoji em Karajá: uma averiguação de ERP durante a compreensão de sentenças também explora propriedades de distributividade em uma língua indígena brasileira, utilizando muito provavelmente pela primeira vez no Brasil, a técnica de EEG-ERP com uma população indígena. $\mathrm{O}$ estudo se desenvolveu no âmbito do projeto guarda-chuva de seu orientador no Programa de Pós-Graduação em Linguística (POSLING-UFRJ) "Pesquisa de campo experimental com línguas indígenas brasileiras", com o apoio do CNPq. Em janeiro de 2015, uma equipe constituída por professores e doutorandos do POSLING-UFRJ, incluindo os orientadores da tese de Cristiane Oliveira da Silva, os professores Marcus Maia e Aniela Improta França, levaram a campo equipamento de EEG de 64 canais e realizaram testes in loco com falantes nativos da língua Karajá, moradores das aldeias Btõiry ou Hãwalò (Ilha do Bananal, TO). Os resultados do teste de oral sentencepicture matching (pareamento de sentenças orais e figuras) realizado por 22 participantes falantes nativos de Karajá, enquanto seus sinais cerebrais eram monitorados pelo equipamento de EEG, permitiram à autora identificar componentes N400 e P600, que indicam que o numeral distributivo Karajá sohoji-sohoji atuaria como um quantificador 
ambíguo, permitindo que leituras evento-distributiva e participantedistributiva fossem licenciadas ou ainda que licenciariam diferentes cenários de verificação para a mesma leitura. A autora conclui, avaliando que a disponibilidade de técnicas cada vez mais sensíveis para aferir o processamento da linguagem pode, de fato, contribuir significativamente para as pesquisas de campo tradicionais e análises formais da linguagem.

Dois estudos neste número da RELIN investigam experimentalmente questões de um tema que vem se tornando cada vez mais presente em Psicolinguística, a saber, o estudo do processamento bilíngue, cujo desafio é o de entender o problema conhecido como one mind, two languages. Em Are bilingualism effects on the L1 byproducts of implicit knowledge? Evidence from two experimental tasks, Souza e Oliveira estudam efeitos do inglês L2 sobre o desempenho linguístico da L1 português brasileiro, na compreensão de construções resultativas, em dois experimentos psicolinguísticos que elaboram sobre estudo anterior dos autores, utilizando, agora, a tarefa maze (on-line), além do julgamento imediato de aceitabilidade (off-line). A tarefa maze, também utilizada no estudo de Marcilese, Rodrigues, Augusto e Henrique, no presente número da RELIN, embora não meça os tempos de leitura dos segmentos em que se dividem as frases, tem sobre a tarefa de leitura automonitorada, a vantagem de não acarretar efeitos spillover e nem demandar questões interpretativas, uma vez que força que o leitor escolha ativamente entre duas opções de continuação da frase. Como se sabe construções resultativas, comuns em inglês (e.g. Samuel wiped the table clean) não se instanciam no repertório de construções do português. A questão que os autores se colocaram no estudo foi a de verificar a influência da L2 sobre a L1, havendo a tarefa on-line se mostrado a única apta a capturar esse efeito, que é analisado pelos autores como um processo implícito.

Soto e Manhães investigam em Morphological priming resists language and modality switching in late Dutch-Brazilian Portuguese bilinguals, o processamento morfológico em bilíngues tardios cuja L1 é o holandês e a L2, o português, em uma tarefa de decisão lexical, coletando tanto tempos de reação, quanto dados cerebrais através de EEG. No experimento, monitoraram-se, através de equipamento eletroencefalográfico, 18 bilíngues proficientes (dados de 3 deles seriam posteriormente retirados do estudo), que deveriam decidir se os itens alvos eram palavras, alternando-se itens em português, holandês e, ainda, como controle, itens em húngaro, língua que nenhum dos 
participantes conhecia. O estudo pretendia testar a Superficial Processing Hypothesis (cf. CLAHSEN; FELSER, 2006; CLAHSEN et al., 2010) que prediz processamento morfológico menos eficiente na L2, e o Revised Hierarchical Model (cf. KROLL et al., 2010) que, entre outras predições, propõe que haja ativação em paralelo de informações lexicais e sublexicais entre línguas. Os resultados obtidos permitem às autoras estabelecer efeitos morfológicos na L2, nas medidas de EEG, mas não nos tempos de reação, sendo a diferença discutida em termos da maior sensibilidade do $\mathrm{N} 400$ a propriedades das raízes do que a palavras inteiras. As autoras concluem que os resultados da alternância entre línguas demonstram priming morfológico nas condições em que a direção se dava de L2 para L1, enquanto que, para a direção de L1 para L2, o efeito oposto ocorreu, confirmando-se as previsões feitas pelo Modelo Revisado Hierárquico.

Os dois artigos que encerram o número tratam de questões relacionadas à leitura de textos que, além de examinadas e avaliadas per se, também apresentam dimensões aplicadas interessantes. Em $\mathbf{O}$ teste de Cloze como instrumento de medida da proficiência em leitura: fatores linguísticos e não linguísticos, Abreu, Garcia, da Hora e Souza apresentam inicialmente uma ampla revisão da literatura sobre o teste de cloze, uma técnica relativamente simples, que vem sendo usada há pelo menos quatro décadas, em que se solicita aos participantes que completem palavras omitidas em textos. Conforme avaliam as autoras, o teste de Cloze tem aplicações educacionais imediatas, servindo de diagnóstico para avaliar-se a compreensão leitora e permitindo intervenções empiricamente fundamentadas. Após a resenha crítica bem orquestrada, as autoras apresentam o seu próprio experimento baseado na técnica, com o objetivo tanto de avaliar a sensibilidade do teste a fatores linguísticos, quanto não linguísticos. Os testes são organizados em um design $2 \times 2$, em que se cruzam as variáveis tipo de palavra (funcional ou lexical) e tamanho do texto (curto ou longo), sendo aplicados a 88 alunos, sendo metade do sexto ano do ensino fundamental e metade do primeiro ano do ensino médio. As autoras analisam, então, os resultados obtidos quantitativa e qualitativamente, argumentando, ao final, em favor da aplicação mais ampla do teste de cloze, que avaliam ser uma ferramenta versátil, capaz de acessar a proficiência leitora em níveis micro e macroestruturais, tendo o potencial de revelar lacunas no letramento em leitura. 


\section{$\mathrm{O}$ artigo $\mathbf{O}$ movimento ocular na leitura realizada por} revisores de textos, de Leite e Magalhaes, teve por objetivo estudar, através da técnica de rastreamento ocular, o processamento da leitura em profissionais de revisão de texto, comparativamente a não revisores, entretendo a hipótese de que a leitura dos revisores seria "menos automática, mais controlada e mais detalhada". Foram submetidos para leitura pelos dois grupos de sujeitos, em tarefa de detecção de erros, 20 parágrafos experimentais, metade com supressão de preposições e metade com anáforas pronominais incorretas, além de 30 textos distratores, parte sem incorreções e parte com diferentes tipos de erros. $\mathrm{O}$ índice de detecção de erros nas frases experimentais não indicou diferença significativa entre os dois grupos de sujeitos, ambos de nível superior. Por outro lado, os resultados das medidas de rastreamento ocular permitiram aos autores confirmarem a sua hipótese inicial de que os revisores profissionais teriam uma leitura mais demorada, menos automática, mais detalhada e controlada. Os autores concluem que a pesquisa pode ser informativa tanto para o estudo da leitura em si, quanto para aferir critérios de desempenho de revisores profissionais.

Em conclusão, avaliamos que os 24 artigos reunidos nesse número temático da RELIN apresentam um panorama único, em que se pode apreciar de forma integrada, pela primeira vez no país, uma amostra significativa de pesquisas, que exercitam diferentes angulações teóricas, através das mais praticadas técnicas experimentais no mundo, no exame de um conjunto amplo de questões relevantes para as principais subáreas da Linguística, verdadeiramente atestando a exuberância da Linguística Experimental no Brasil. Esperamos que esses trabalhos sejam fonte de inspiração para novas pesquisas teóricas e experimentais.

\section{Referências}

BADECKER, W.; STRAUB, K. The processing role of structural constraints on the interpretation of pronouns and anaphora. Journal of Experimental Psychology. Learning, Memory, and Cognition, Washington, v. 28, p.748-769, 2002. DOI: http://dx.doi.org/10.1037//02787393.28.4.748.

CHOMSKY, N. Lectures on government and binding. Dordrecht: Foris, 1981. 
CHOMSKY, N. The Minimalist Program. Cambridge, MA: MIT Press, 1995.

CLAHSEN. H.; FELSER. C. Grammatical processing in language learners. Applied Psycholinguistics, Cambridge University Press, v. 27, p. 3-42, 2006.

CLAHSEN, H.; FELSER, C.; NEUBAUER, K.; SATO, M; SILVA. R. Morphological structure in Native and Non-Native Language Processing Language Learning, Wiley Online Library, v. 60, p. 21-43, 2010.

COSTA, M. U. C. L. M. Argument Stucture in Language Acquisition: an ERP Study. 2015. 174f. Tese (Doutorado em Linguística) - Faculdade de Letras, Universidade Federal do Rio de Janeiro, Rio de Janeiro, 2015.

FILLMORE, C. Frame semantics. In: The Linguistic Society of Korea (Ed.). Linguistics in the morning calm: selected papers from SICOL-1981. Seoul, Korea: Hashin Publishing Co., 1982. p. 111-137. [Reprinted in: GEERAERTS, D. (Ed.). Cognitive Linguistics: Basic Reading. Berlin: Mouton de Gruyter, 2006.]

FILLMORE, C. Valency issues in FrameNet. In: HERBST, T.; GÖTZVOTTELER, K. (Ed.). Valency: theoretical, descriptive and cognitive issues. Berlin: Mouton de Gruyter, 2007. p. 129-160.

FRAZIER, L. On comprehending sentences: syntactic parsing strategies. 1979. Tese (Doutorado) - University of Connecticut, 1979. [reproduzida por Indiana University Linguistics Club]

FRAZIER, L.; CLIFTON, C. Construal. MIT Press Cambridge, 1996.

GLUCKSBERG, S.; KEYSAR, B. Understanding metaphorical comparisons: beyond similarity. Psychological Review, American Psychological Association, v. 97, n. 1, p. 3-18, 1990. DOI: https://doi. org/10.1016/S1364-6613(02)00040-2.

HILL, A. (Ed.) Third Texas conference on problems of linguistic analysis in English. Second discussion section. Austin: University of Texas, 1962.

KROLL, J. F.; HELL, J. G. van; TOKOWICZ, N.; GREEN, D. The revised hierarchical model: a critical review and assessment. Bilingualism: Language and Cognition, Cambridge University Press, v. 13, n. 3, p. 373-381, July, 2010. DOI: https://doi.org./10.1017/S136672891000009X. 
LANGACKER, R. W. Foundations of cognitive grammar: theoretical prerequisites. Stanford: Stanford University Press, 1987.

LANGACKER, R. W. Essentials of cognitive grammar. Oxford: Oxford University Press, 2013.

LIMA, Suzi. A estrutura argumental dos verbos na língua Juruna (Yudja): da formação dos verbos para a análise das estruturas sintáticas. 2008. Dissertação (Mestrado) - Universidade de São Paulo, São Paulo, 2008.

MAGALHÃES, J. O.; MAIA, M. Pistas prosódicas implícitas na resolução de ambiguidades sintáticas: um caso de adjunção de atributos. Revista da ABRALIN, Florianópolis, v.5, n.1-2, p.143-167, 2006.

MAIA, M. A. R. Sintaxe experimental. In: OTHERO, Gabriel; KENEDY, Eduardo. (Org.). Sintaxe, sintaxes. São Paulo: Editora Contexto, 2015. p. 51-72.

MODESTO, M. What Brazilian Portuguese says about control: remarks on Boeckx \& Hornstein. Syntax, Wiley Online Library, v. 13, n. 1, p. 7896, 2010.

MODESTO, M. Inflected infinitives in Brazilian Portuguese and the theory of control. In: GONÇALVES, A. (Org.). Complement clauses in Portuguese: syntax and acquisition. Amsterdam: John Benjamins. 2016a. In press.

PHILLIPS, C.; WAGERS, M. W.; LAU, E. F. Grammatical illusions and selective fallibility. In: RUNNER, J. (Ed.). Experiments at the interface. Syntax \& Semantics. Bingley, UK: Emerald Publications, 2011. v. 37, p. 153-186.

REINHART, T.; REULAND, E. Reflexivity. Linguistic Inquiry, MIT Press, v. 24, n. 4, p. 657-720, 1993.

RODRIGUES, C.; HORNSTEIN, N. Epicene agreement and inflected infinitives when the data is "Under Control": a reply to Modesto (2010). Syntax, Wiley Online Library, v. 16, p. 292-309, 2013.

STEFANOWITSCH, A. Cognitive linguistics as a cognitive science. In: CALLIES, M.; KELLER, W. R.; LOHÖFER, A. (Ed.) Bidirectionality in the cognitive sciences. Amsterdam; Philadephia: John Benjamins, 2011. p. 296-309. DOI: https://doi.org/10.1075/hcp.32.16ste. 